\title{
Transmittance and Extinction Coefficient of Sea and Well-Water in Mombasa County, Kenya
}

\author{
Charles Mogunde ${ }^{1}$, Cliff Orori Mosiori ${ }^{2}$ \\ ${ }^{1}$ Kenyatta University \\ P. 0. Box 43844-00100, Nairobi, Kenya \\ 2 Technical University of Mombasa \\ P. 0. Box 90420-80100, Mombasa, Kenya
}

DOI: $10.22178 /$ pos.39-4

LCC Subject Category: TP155-156, QC450-467, QD450-801

Received 06.12.2017

Accepted 20.08.2018

Published online 31.10.2018

Corresponding Author:

Charles Mogunde

mogundecharles@gmail.com

(c) 2018 The Authors. This article is licensed under a Creative Commons Attribution 4.0 License @ (1)

\begin{abstract}
Using a laser transmitter in the range of $200 \mathrm{~nm}$ to $1200 \mathrm{~nm}$, transmittance and total extinction coefficients were determined for two different but close related optical media which are ocean water and shallow well water in Mombasa County, in Kenya. The results were interpreted using LambertBeer's law as applied for very small ranges of concentrations. It was established that the total extinction coefficients for two forms of water showed linearity with values of total extinction coefficients found to be $\mu \mathrm{t}=7.734\left(\mathrm{~g} / \mathrm{ml}^{-1} \mathrm{~mm}^{-1}\right.$ and $\mu \mathrm{t}=$ $127.6 \mathrm{~mm}^{-1}$ at a wavelength of $638 \mathrm{~nm}$ for ocean water and shallow well water respectively.
\end{abstract}

Keywords: Lambert-Beer's law; attenuation; nanoparticles; energy radiated; seawater; absorption; scattering.

\section{INTRODUCTION}

In optical applications, water is usually assumed to be transparent to electromagnetic radiations within the visible spectrum. Somehow, it is taken as opaque to wavelengths above the visible spectra and those below it. Based on this assumption, visible light in water undergoes refraction and attenuation [4]. The amount to which refraction take place is called refractive index [1] which is subject to its state of salinity and temperature. The refractive index increases with increasing salinity and decreasing temperature. In scientific studies, refractive index of a sample of seawater used in this study was at a constant temperature. In real cases, water may have some cloudiness caused by suspensions of dissolved nanoparticles materials [10] such that when a light beam incident on it undergoes through two different phenomena, absorption, and scattering [9]. Absorption hampers propagation while scattering which is caused by the refractive index mismatch at microscopic boundaries [13]. Finally, some de- crease is evident due to ray re-direction as a result of the photon absorption leading to a concept of extinction or energy attenuation of the incident light energy [8].

\section{THEORETICAL PRINCIPLES}

In any form of a fluid, intensity of radiation with respect to wavelength $\lambda$ decreases in the direction of the light beam [14]. Ideally, the decrease at the infinitesimal thickness, $x$, is proportional to the intensity of energy radiated, $I$, as [6]:

$$
d I_{\lambda}=-\chi_{\lambda} I_{\lambda} d x
$$

The coefficient of proportionality, $\chi$, is called the absorption coefficient, which can be obtained by integrating Equation (1) in the limits $(x=h$ and $x$ $=h+L$ ), to obtain [11]: 


$$
\chi_{\lambda}=\frac{2.30}{L}\left(\log I_{\lambda, h}-\log I_{\lambda,(h+L)}\right)
$$

From Equation (2) a factor of 2.30 is applied because the logarithm used is of base-10, $L$ is the thickness of the layer within which the energy of the radiation is reduced from $I_{(\lambda, h)}$ to $I_{\lambda,(h+L) \text {. The }}$ absorption coefficient depends upon the unit of length which $L$ is expressed. The decrease of intensity in water depends upon the amount of radiation that is absorbed and scattered. Purified water has its scattering due to water molecules $[4,8,15]$. The scattering effect is not easy to separate as it includes absorption coefficient which is a factor of wavelength, discrepancies has been reported and due to these discrepancies, the absorption in pure water is still in dispute as portrayed in Table 1 .

Table 1 - Reported absorption coefficients [6]

\begin{tabular}{|l|c|c|}
\hline \multicolumn{1}{|c|}{ Author (s) } & Year & $\begin{array}{l}\text { Absorption } \\
\text { coefficients }\end{array}$ \\
\hline $\begin{array}{l}\text { Hüfner and } \\
\text { Albrecht }\end{array}$ & 1891 & 0.048 \\
\hline Ewan & 1895 & 0.030 \\
\hline Aschkinass & 1895 & 0.020 \\
\hline Sawyer & 1931 & 0.015 \\
\hline
\end{tabular}

Lambert-Beer's law for low concentrations empirically relates to light absorption and scattering of the material as [5]:

$$
I=I_{o} \exp \left(-\mu_{t} \times c \times r\right)
$$

so that:

$$
\mu \times c=\ln \left(\frac{I_{o}}{I}\right) \times \frac{1}{r}
$$

where $I_{0}$ - is the intensity of the incident light; $I$ is the intensity of the transmitted light; $r$ - is the thickness of the sample; $c$ - is the concentration of the sample; $\mu t$ - is the total extinction coefficient of the sample.

\section{EXPERIMENT PROCEDURES}

A laser source emitter transmitting at a spectral range from $200 \mathrm{~nm}$ to $1200 \mathrm{~nm}$ was employed directed to a $20 \mathrm{~mm}$ thick transparent glass sam- ple carrier. A sensitive multi-range meter able to measure currents up to $20 \mathrm{nA}$ was used. Two samples of ocean water and another sample of shallow well-water were used.

\section{RESULTS AND DISCUSSION}

By geographical definition, a water well can be defined as an excavation or structure created in the ground by digging, driving, boring, or drilling to access groundwater in underground aquifers [8]. This implies that if it ever gave the result to water, then the water is drawn by a pump, or using containers, such as buckets, that are raised mechanically or by hand. Deeper wells are excavated by hand drilling methods or machine drilling. Drilled wells can access water at much greater depths than dug wells [5]. Therefore, there are two broad classes classified as shallow or unconfined wells completed within the uppermost saturated aquifer at that location, and as deep or confined wells, sunk through an impermeable stratum into an aquifer beneath. Well, water is known to contain naturally occurring minerals, such as calcium, iron, and sulfur [3]. These present excess quantities over water molecules. Therefore, the results obtained were plotted and represented graphically. Transmittance against concentration for ocean water and well water was represented in Figures 1, 2.

Transmittance as an optical property of the surface of a material is defined as the effectiveness in transmitting radiant energy as received at and past the surface [14]. Therefore it is indeed the fraction of incident electromagnetic power that is transmitted through a sample, in contrast to the transmission coefficient [10]. Therefore, it is well defined when taken as the ratio of the transmitted to the incident electric field which thus includes internal transmittance which is the energy loss by absorption as compared to total transmittance which is due to absorption, scattering, reflection, and related optical properties.

As observed in Figure 3 and Figure 4 show that the transmitted intensities decrease exponentially with concentration for both ocean water and shallow well-water. In photometry [1], luminous intensity is a measure of the wavelengthweighted power emitted by a light source in a particular direction per unit solid angle, based on the luminosity function, a standardized model of the sensitivity of the human eye. Thus, the graph depicts the luminous intensity of the two samples. 


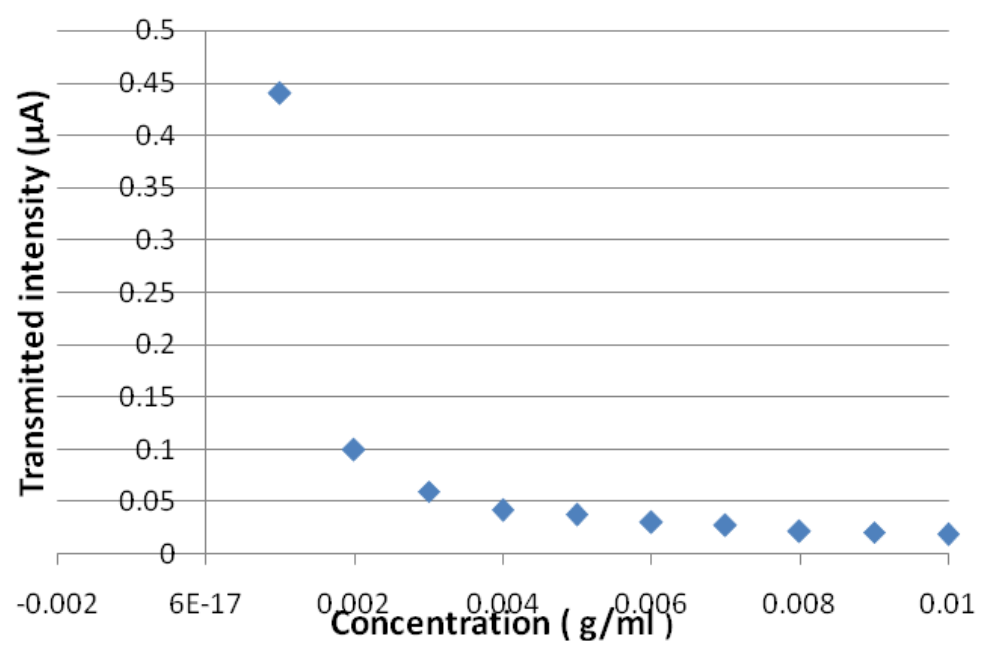

Figure 1 - Transmitted intensity versus concentration for ocean water

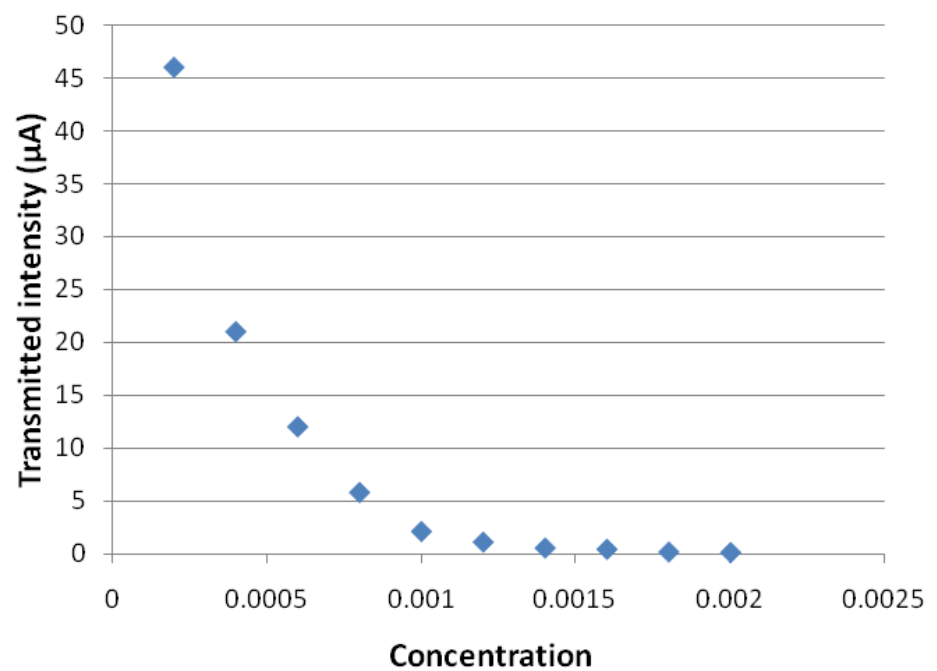

Figure 2 - Transmitted intensity versus concentration for shallow well-water

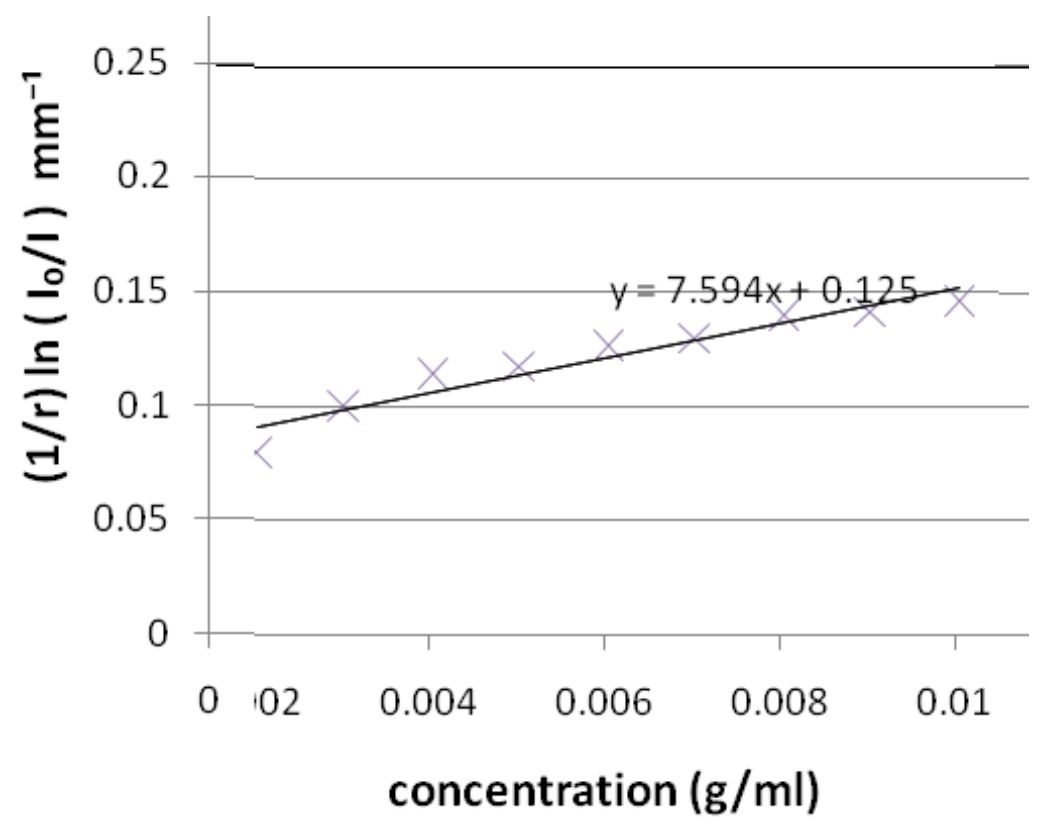

Figure 3 - Relationship of $(1 / r) \ln \left(I_{0} / l\right)$ versus concentration for ocean water 


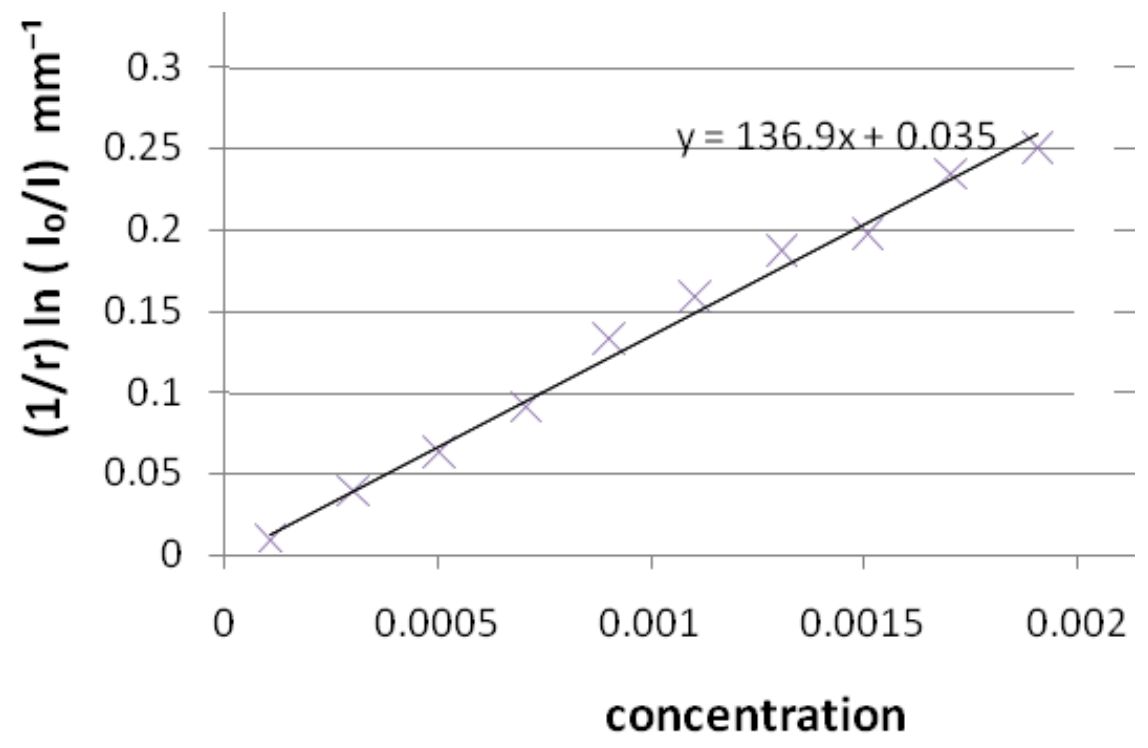

Figure 4 - Relationship of $(1 / r) \ln \left(I_{0} / l\right)$ versus concentration for shallow well-water

The exponential decrease confirms the applicability of Lambert-Beer's law in the range of concentrations considered in this analysis which states that that absorbance of a material sample is directly proportional to its thickness. Based on absorbance, Beer's law is stated that absorbance is proportional to the concentrations of the attenuating species in the material sample [7]. Therefore, if a compound absorbs light, then its absorption spectrum is a unique property of that compound. This implies that the molecular structure is responsible for the absorption properties and thus the most common feature of absorbing compounds are conjugated double bonds, often as an aromatic ring.

As observed in Figure 1 and Figure 3, the results of ocean water was for measurements of concentrations ranging from $0.002 \mathrm{~g} / \mathrm{ml}$ to $0.010 \mathrm{~g} / \mathrm{ml}$ in steps of $0.001 \mathrm{~g} / \mathrm{ml}$ whereas Figure 2 and Figure 4 are for referring sampled shallow well water for concentrations ranging from 0.0002 to 0.0020 in steps of 0.0002 . From the results linear fitted measurements were taken and the slope obtained represents the total extinction coefficient $\mu \mathrm{t}$. Thus the intercept noted is very small relative to the slope value. Therefore, the total extinction coefficient, $\mu t$, of $7.734(\mathrm{~g} / \mathrm{ml})^{-1} \mathrm{~mm}^{-1}$ for diluted concentrations of ocean water at 638 $\mathrm{nm}$ and total extinction coefficient for shallow well water was $\mu t=127.6 \mathrm{~mm}^{-1}$ at $638 \mathrm{~nm}$. These reported values of total extinction coefficient depended on wavelength [12] only. Therefore, the linearity of the result shows that Equation (1) related well in the range of concentrations considered in this study [15]. It was not established whether the extinction coefficient for ocean water depends on the place of ocean water considered just as well water.

\section{CONCLUSIONS}

It was established that the total extinction coefficients for two forms of water showed linearity of the results obtained in Figures 3, 4. This was in agreement with Lambert-Beer's law in the range of concentrations considered in this study. From these results, values of total extinction coefficients for ocean water and shallow well water were found to be $\mu \mathrm{t}=7.734\left(\mathrm{~g} / \mathrm{ml}^{-1} \mathrm{~mm}^{-1}\right.$ and $\mu \mathrm{t}=127.6 \mathrm{~mm}^{-1}$ at a wavelength of $638 \mathrm{~nm}$ respectively.

\section{REFERENCES}

1. Abebe, E. (2007). Determination of Fat and Protein Content of Ocean water using He-Ne Laser Light Scattering (Master's thesis), Addis Ababa University. Retrieved from http://etd.aau.edu.et/bitstream/handle/123456789/2909/Ermias\%20Abebe.pdf?sequence=1 \&isAllowed=y 
2. Alikas, K., Kratzer, S., Reinart, A., Kauer, T., \& Paavel, B. (2015). Robust remote sensing algorithms to derive the diffuse attenuation coefficient for lakes and coastal waters. Limnology and Oceanography: Methods, 13(8), 402-415. doi: 10.1002/lom3.10033

3. Chen, R. S., Ab Ghani, M. H., Salleh, M. N., Ahmad, S., \& Tarawneh, M. A. (2014). Mechanical, water absorption, and morphology of recycled polymer blend rice husk flour biocomposites. Journal of Applied Polymer Science, 132(8), 414-494. doi: 10.1002/app.41494

4. Collaud Coen, M., Weingartner, E., Schaub, D., Hueglin, C., Corrigan, C., Henning, S., ... Baltensperger, U. (2004). Saharan dust events at the Jungfraujoch: detection by wavelength dependence of the single scattering albedo and first climatology analysis. Atmospheric Chemistry and Physics, 4(11/12), 2465-2480. doi: 10.5194/acp-4-2465-2004

5. Frey, K. E., Perovich, D. K., \& Light, B. (2011). The spatial distribution of solar radiation under a melting Arctic sea ice cover. Geophysical Research Letters, 38(22). doi: 10.1029/2011gl049421

6. Gwamuri, J, Gholap, A. V., Shartir, T. S. M., \& Bassuah, P. K. (2006). Investigating Light Propagation in Turbid Media by Evaluating Optical Properties of Phantom Tissues. Retrieved from https://www.researchgate.net/publication/268402864_Investigating_Light_Propagation_In_Tu rbid_Media_By_Evaluating_Optical_Properties_Of_Phantom_Tissues

7. Harvey, H. W. (2015). Biological chemistry and physics of sea water. Cambridge: Cambridge University Press.

8. Kafodya, I., Xian, G., \& Li, H. (2015). Durability study of pultruded CFRP plates immersed in water and seawater under sustained bending: Water uptake and effects on the mechanical properties. Composites Part B: Engineering, 70, 138-148. doi: 10.1016/j.compositesb.2014.10.034

9. Lee, M. E., \& Lewis, M. R. (2003). A new method for the measurement of the optical volume scattering function in the upper ocean. Journal of Atmospheric and Oceanic Technology, 20(4), 563-571.

10. Lee, Z., Wei, J., Voss, K., Lewis, M., Bricaud, A., \& Huot, Y. (2015). Hyperspectral absorption coefficient of "pure" seawater in the range of 350-550 nm inverted from remote sensing reflectance. Applied Optics, 54(3), 546. doi: 10.1364/ao.54.000546

11. Liu, J., Liu, Y., Liu, N., Han, Y., Zhang, X., Huang, H., ... Kang, Z. (2015). Metal-free efficient photocatalyst for stable visible water splitting via a two-electron pathway. Science, 347(6225), 970-974. doi: 10.1126/science.aaa3145

12. Mattison, K., Morfesis, A., \& Kaszuba, M. (2003, December). A primer on Particle Sizing by Static Laser light Scattering. Retrieved from https://www.researchgate.net/publication/237663975_A_Primer_on_Particle_Sizing_Using_Dy namic_Light_Scattering

13. Min, C., Nie, P., Tu, W., Shen, C., Chen, X., \& Song, H. (2015). Preparation and tribological properties of polyimide/carbon sphere microcomposite films under seawater condition. Tribology International, 90, 175-184. doi: 10.1016/j.triboint.2015.04.027

14. Rossing, T. (2015). Springer Handbook of Acoustics. New York: Springer.

15. Srinivasan, R., Kumar, D., \& Singh, M. (2002). Optical Tissue-Equivalent Phantoms for Medical Imaging. Trends Biomater. Artif. Organs., 15, 42-47.

16. Wang, T., Yang, Z., \& Copping, A. (2013). A Modeling Study of the Potential Water Quality Impacts from In-Stream Tidal Energy Extraction. Estuaries and Coasts, 38(S1), 173-186. doi: 10.1007/s12237-013-9718-9 